\title{
Fertility and breast cancer: Recommendations of the 2019 Izmir Consensus Conference
}


Sevilay Altıntaş ${ }^{8}\left(\right.$ ID), Mustafa Emiroğlu ${ }^{9}\left(\right.$ ID), Kemal Atahan ${ }^{10}$ (ID), Funda Göde ${ }^{7}\left(\right.$ ID), Cemal PosacI ${ }^{2}$ (ID), Öner Menteş ${ }^{11}$ (ID), Bahadır Saatli' (ID),



\footnotetext{
${ }^{1}$ Department of General Surgery, Dokuz Eylul University School of Medicine, Izmir, Turkey

${ }^{2}$ Department of Obstetrics and Gynecology, Dokuz Eylul University School of Medicine, Izmir, Turkey

${ }^{3}$ Department of Obstetrics and Gynecology, Uludag University School of Medicine, Bursa, Turkey

${ }^{4}$ Department of General Surgery, Marmara University School of Medicine, Istanbul, Turkey

${ }^{5}$ Department of Obstetrics and Gynecology, Ondokuz Mayis University School of Medicine, Samsun, Turkey

${ }^{6}$ Department of General Surgery, Kocaeli University School of Medicine, Kocaeli, Turkey

${ }^{7}$ Department of Obstetrics and Gynecology, MedicalPark Izmir Hospital, Izmir, Turkey

${ }^{8}$ Department of Medical Oncology, Antwerp University Hospital, Antwerp, Belgium

${ }^{9}$ Clinic of General Surgery, Tepecik Training and Research Hospital, Izmir, Turkey

${ }^{10}$ Department of General Surgery, Katip Celebi University School of Medicine, Izmir, Turkey

${ }^{11}$ Corapcioglu Medikal Danismanlik, Ankara, Turkey

${ }^{12}$ Clinic of Obstetricas and Gynecology, TepecikTraining and Research Hospital, Izmir, Turkey

${ }^{13}$ Department of General Surgery, Okan University School of Medicine, Istanbul, Turkey
}

Cite this article as: Koçdor MA, Doğan E, Kasapoğlu I, Güllüoğlu B, Güven D, Cantürk NZ, et al. Fertility and breast cancer: Recommendations of the 2019 Izmir Consensus Conference. Turk J Surg 2020; 36 (1): 119-120.

\section{Corresponding Author}

\section{Mehmet Ali Koçdor}

E-mail: mehmet.kocdor@deu.edu.tr

Received: 02.11 .2019

Accepted: 29.01.2020

Available Online Date: 18.03.2020

O Copyright 2020 by Turkish Surgical Society Available online at www.turkjsurg.com

DOI: $10.5578 /$ turkjsurg.4654
Dear Editor,

The most important expectation of a healthy young woman is to have a healthy pregnancy. No matter how strong she is psychologically, diverging from pregnancy expectation is a very difficult situation to accept for an infertile woman aside from being concerned of her life with cancer or probable cancer diagnosis (1). Current data suggests that breast cancer is not generally a contra-indication for pregnancy and/also pregnancy does not have a negative impact on the prognosis of breast cancer in patients with no existing local and systemic diseases and completed their standard treatments $(2,3)$. Therefore, pregnancy expectation is quite natural in breast cancer cases which subsist a disease-free survival expectation.

The 2019 Symposium of Turkish Society of Reproductive Medicine (TSRM) was held together with the Turkish Senology Academy (SENATURK) under the theme of "Fertility and Breast Cancer" in Izmir, in May $18^{\text {th }}-19^{\text {th }}, 2019$. Gynecologists specialized in fertility, general surgeons specialized in breast cancer and numerous family physicians participated actively to the meeting. Intended for family physicians, "Basic Concepts in Infertility", "The Role of Family Physician from Infertility to Birth" and "Critical Points of Breast Diseases in First Step" courses were performed with intense interest on the first day of the meeting.

The second day, the most comprehensive onco-fertility symposium based on breast cancer was performed for the first time in our country. The conferences titled "Breast Radiology-Suspicious Lesion Follow-up in Pregnancy", "Risk Consulting in Hereditary Breast Cancer Cases", "Risk Reducing Breast Surgery" and "The Role of Breast Surgeon in Planning Pregnancy" were performed in the Breast Cancer for Gynecologists Session. "Current Situation on Freezing and Transplantation of the Over Tissue", "Endometrial Follow-up During the Adjuvant Hormonal Treatment", 
"Systemic Treatment of Breast Cancer in Infertile Women", "Preservation Modalities for Fertilization During the Chemotherapy", "Urgent Ovulation Induction Before Chemotherapy" and "Current Situation in Oocyte cryopreservation" were performed in the Preservation of Fertility in Oncological Cases Session. It appeared within these conferences that laboratories and technical infrastructure are available in many centers in Turkey, in which all contemporary applications intended for providing and preserving fertility in oncological cases are being performed successfully. These two disciplines performed a consensus panel in order to determine the principles peculiar to our country at the end of these conferences with critical subjects. The following articles were determined as basic principles by considering all the scientific data collected to date.

\section{RECOMMENDATIONS, CONCENSUS ARTICLES}

1. All fertile breast cancer survivors have the right to plan pregnancy and give healthy birth, except for the systemic disease and apparent low life expectation cases as the cure is in question -though the rates may differ-.

2. Patients should be informed that they have a pregnancy chance by the breast physician, especially at the diagnosis period, for the breast cancer cases aged forty and below. These cases should absolutely be questioned and recorded for their pregnancy expectations and wishes.

3. Breast cancer cases having the wish and expectation of pregnancy should be guided to the infertility clinic instead of standard gynecology clinics scarcely at the diagnosis period.

4. In cases showing BI-RADS 5 lesion in their breast radiograms and at the same time in pregnancy, expectations should be subjected to preparations in aspects of planning the fertility method and completing the related analyses and investigations until the histopathologic diagnosis is reached.

5. In mutation carriers with high breast cancer risk, in cases with strong family history or high risk histopathology in their biopsies, risk reducing surgery should be suggested before planned pregnancy if possible. As for the low level over reserve cases, risk reduction procedures may be shifted post embryo/oocyte cryopreservation.

6. When pregnancy consists in highly risked cases as stated in article 5, it cannot be terminated unless the family demands for it. However, these cases should be close-monitored by the breast surgeon and an experienced radiologist. This observation is continued post birth period and risk reducing procedures are suggested to the patient after the non-long-term of lactation.

7. Chemotherapy agents are gonadotoxic in variable ratios. However, considering pregnancy expectation, standard systemic treatment protocols including endocrine treatment cannot be changed. Embryo/oocyte cryopreservation before chemotherapy is the first choice for potential pregnancy for cases with a pregnancy wish. Embryo/oocyte cryopreservation before the planned standard treatment scheme has a critical importance due to the decrease in over reserve and permanent amenorrhea contingency, and cases should be encouraged towards this aspect. Pregnancy contingency with transferred embryos is almost equal to normal population in the light of current data (4).

8. Over suppression with $\mathrm{GnRH}$ analogs during chemotherapy is not an alternative application to embryo/oocyte cryopreservation. However, there is no objection in applying it independently from the estrogen receptor state of the breast tumor in order to preserve the ovary functions.

9. Ovulation induction and embryo/oocyte cryopreservation should be performed URGENTLY right from the histopathologic diagnosis by the infertility clinic within the protocols framework determined by TSRM. Transfer timing is determined multidisciplinarily upon the opinions of Fertility Breast clinic, considering the special/biological condition and the cure/progression state of the patient after systemic treatment is completed. Pregnancy decision of the patient and her family is the main determinant unless there is a disease case showing progression.

\section{CONCLUSION}

All young, early breast cancer patients should be informed of their pregnancy chances provided that the current standard treatments are completed; and if desired, urgent oocyte stimulation and embryo/oocyte cryopreservation processes should be completed before systemic chemotherapy. However, this special condition should be carried out in cooperation with fertility clinics and general surgery clinics where intense breast tumor surgeries are performed.

\section{REFERENCES}

1. Pagani O, Partridge A, Korde L, Badve S, Bartlett J, Albain K, et al. Pregnancy after breast cancer: if you wish, Ma'am. Breast Cancer Res Treat 2011;129:309-17. [CrossRef]

2. Azim HA, Santoro L, Pavlidis N, Gelber S, Kroman N, Azim H, et al. Safety of pregnancy following breast cancer diagnosis: a meta-analysis of 14 studies. Eur J Cancer 2011;47:74-83. [CrossRef]

3. Ploquin A, Pistilli B, Tresch E, Frenel JS, Lerebours F, Lesur A, et al. 5-year overall survival after early breast cancer diagnosed during pregnancy: a retrospective case-control multicentre French study. Eur J Cancer 2018;95:30-7. [CrossRef]

4. Lambertini M, Goldrat O, Clatot F, Demeestere I, Awada A. Controversies about fertility and pregnancy issues in young breast cancer patients: current state of the art. Curr Opin Oncol 2017;29:243-52. [CrossRef] 